University of Wollongong

Research Online

Faculty of Engineering and Information

Faculty of Engineering and Information

Sciences - Papers: Part A

Sciences

$1-1-2012$

Acoustic emission monitoring of split formation during Charpy impact testing of high strength steel

Andrii Kostryzhev

University of Birmingham, andrii@uow.edu.au

R B. Punch

University of Birmingham

Claire L. Davis

University of Birmingham

Martin Strangwood

University of Birmingham

Follow this and additional works at: https://ro.uow.edu.au/eispapers

Part of the Engineering Commons, and the Science and Technology Studies Commons

Research Online is the open access institutional repository for the University of Wollongong. For further information contact the UOW Library: research-pubs@uow.edu.au 


\title{
Acoustic emission monitoring of split formation during Charpy impact testing of high strength steel
}

\author{
Abstract \\ Acoustic emission (AE) monitoring has been used to detect split formation during room temperature low \\ blow Charpy impact testing of high strength thick strip steels. The AE signal analysis identified separate \\ signals originating from hammer impact, plastic deformation (verified using Charpy impact testing on \\ mild steel with no splits) and split initiation/growth. The presence of splits was confirmed by sectioning \\ and fractography, and the splits were brittle in nature. A possible correlation between the AE signal \\ features and fracture mode is presented.

\section{Keywords} \\ testing, charpy, during, formation, split, monitoring, emission, acoustic, strength, steel, high, impact \\ Disciplines \\ Engineering | Science and Technology Studies

\section{Publication Details} \\ Kostryzhev, A. G., Punch, R. B., Davis, C. L. \& Strangwood, M. (2012). Acoustic emission monitoring of split \\ formation during Charpy impact testing of high strength steel. Materials Science and Technology, 28 (2), \\ 240-242.
}




\title{
ACOUSTIC EMISSION MONITORING OF SPLIT FORMATION DURING CHARPY IMPACT TESTING OF HIGH STRENGTH STEEL
}

\author{
Andrii G. Kostryzhev ${ }^{1}$, Rachel B. Punch ${ }^{2}$, Claire L. Davis ${ }^{2}$, Martin Strangwood ${ }^{2}$ \\ ${ }^{1}$ School of Electronic, Electrical and Computer Engineering; \\ ${ }^{2}$ School of Metallurgy and Materials; \\ University of Birmingham, Edgbaston, Birmingham, B15 2TT, United Kingdom \\ kostryzhev@yahoo.com (corresponding author)
}

\begin{abstract}
Acoustic emission (AE) monitoring has been used to detect split formation during room temperature low blow Charpy impact testing of high strength thick strip steels. AE signal analysis identified separate signals originating from the hammer impact, plastic deformation (verified using Charpy impact testing on mild steel with no splits) and split initiation/growth. The presence of splits was confirmed by sectioning and fractography and the splits were brittle in nature. A possible correlation between the AE signal features and fracture mode is presented.
\end{abstract}

Key words: acoustic methods, steel, impact test, splits, fracture.

\section{Introduction}

The use of acoustic emission (AE) monitoring, during tensile testing of steels, has shown an increase in AE activity after the yield point in ferritic [1-3] and austenitic [4] steels, due to an increase in dislocation motion. During fatigue testing AE activity increased after crack on-set in ferritic [5-8], austenitic [9] and dual-phase [10,11] steels, due to the appearance of a crack growth signal in addition to the plastic deformation signal. However, the absolute number of AE events during fatigue testing has been observed to be dependent on the steel microstructure and mechanical properties [5, 6], mode of loading and sample geometry $[11,12]$, and the presence of a chemically aggressive environment [13, 14]. Analysis of AE signals obtained during impact testing of fatigue pre-cracked Charpy specimens of a dual-phase steel has been able to separate the time at which AE activity is dominated by plastic deformation from that associated with crack growth [15]. In the present paper the preliminary results of AE monitoring during Charpy impact testing of high strength strip steel, which show splits on the ductile fracture surface of the upper transition regions, are presented.

\section{Materials and experimental techniques}

Low blow Charpy impact tests were carried out using standard 55x10x10 mm specimens made from an annealed low carbon mild steel and an as-rolled strip steel (0.063C-1.61Mn-0.097Si-0.980Ni$0.105 \mathrm{Mo}-0.066 \mathrm{Nb}-0.089 \mathrm{Ti}-0.007 \mathrm{~V}$ wt\%) provided by Tata Steel UK Ltd. Testing was carried out at room temperature using an Instron Charpy testing machine at 20, 40, 60, 80 and $100 \mathrm{~J}$ impact energies. Room temperature failure energies were measured to be $125 \mathrm{~J}$ for the high strength steel and $180 \mathrm{~J}$ for the mild steel. Acoustic emission was recorded on an industrial hardware station using 1 broadband single piezoelectric sensor, a preamplifier of 2/4/6 type and AEWin for PCI2 version E3.61 software, produced by Physical Acoustics Corporation (USA). AE signal analysis was carried out using AEWin and Wave Viewer E1.11 software. The sensor was non-permanently attached using white soft paraffin to one end of the Charpy sample and data were collected by wave streaming. 


\section{Results and discussion}

During the low blow impact testing of the mild steel two different AE signatures were recorded: from the hammer impact and elastic deformation of the machine, and from plastic deformation of the sample (Fig. 1). Post impact inspection showed the mild steel samples were bent through an angle in the range of $3^{0}-27^{0}$ (Fig. 2). No cracking was observed. The power spectrum of the acoustic wave part originating from plastic deformation exhibited its highest peak below $50 \mathrm{kHz}$. No significant variation in acoustic signature was observed with an increase in impact energy from $40 \mathrm{~J}$ to $100 \mathrm{~J}$. A slight (by up to $10 \mathrm{~dB}$ ) increase in signal amplitude with an increase in impact energy can be related to an increase in the volume of the sample that is plastically deformed. This is consistent with the effect of deformed sample volume on AE activity reported earlier for tensile testing of steel [3].

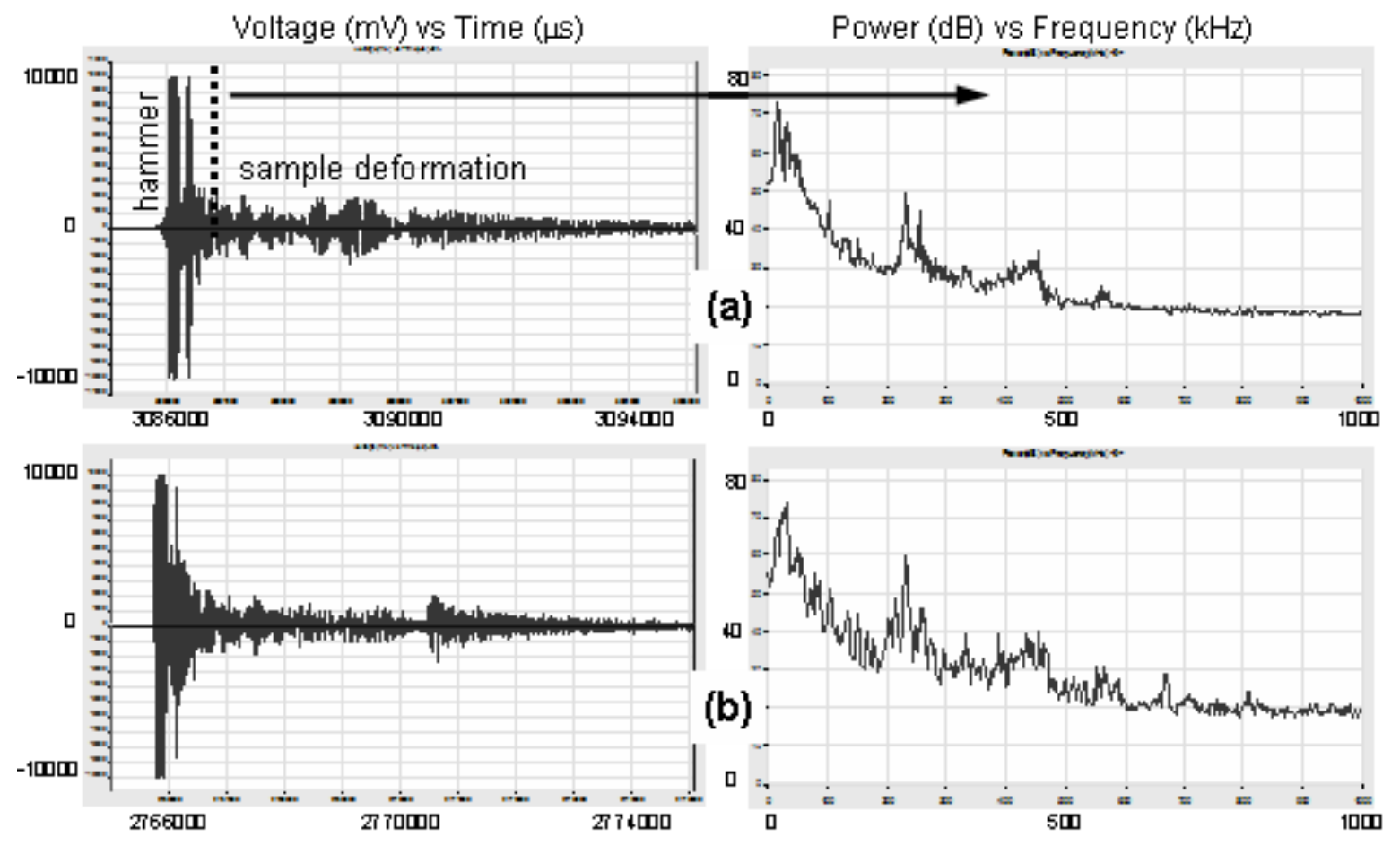

Figure 1 Acoustic waves (left) and power spectra (right) for the sample deformation stage during testing of mild steel at (a) $60 \mathrm{~J}$ and (b) $80 \mathrm{~J}$ impact energies. 


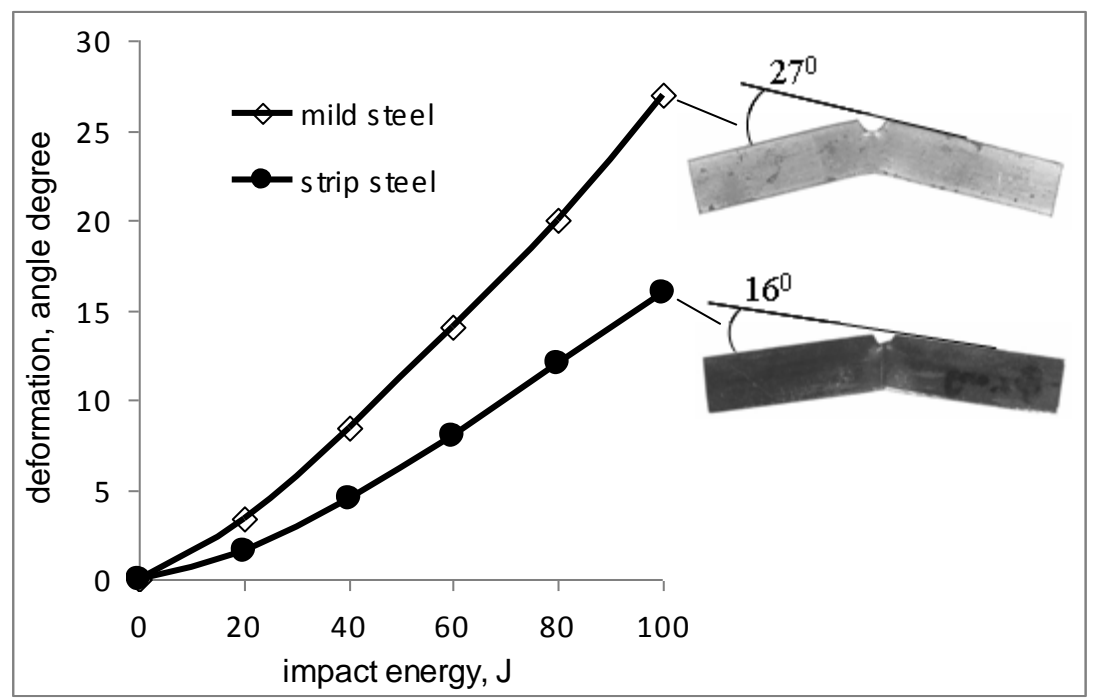

Figure 2 The dependence of sample deformation on impact energy

(photo images of the mild and strip steel samples after testing at $100 \mathrm{~J}$ are inserted).

In contrast to the mild steel tests, the AE response for the strip steel tests varied with impact energy (Fig. 3). Two separate AE signatures were observed during testing at 40 and $60 \mathrm{~J}$ : from the hammer impact and elastic deformation of the machine, and from the sample plastic deformation (Fig. 3, a); whilst three AE signatures were observed during testing at $80 \mathrm{~J}$ and $100 \mathrm{~J}$ : from hammer impact and elastic deformation of the machine, from the sample plastic deformation and from crack (split) initiation (Fig. 3, b). The occurrence of splits during the low blow testing was confirmed by post-test microscopic examination of sectioned samples (Fig. 4, a). The predominant fracture mode for the splits was transgranular cleavage (Fig. 4, b). The power spectrum of the acoustic wave part originating from the sample plastic deformation exhibited the highest peak below $50 \mathrm{kHz}$, as also seen for the mild steel sample. Similarity in the AE power spectra for plastic deformation of both steels was expected, as their microstructures are predominantly ferrite. The power spectrum of the acoustic wave part originating from split crack initiation and growth exhibited two peaks in the $200-500 \mathrm{kHz}$ frequency range and three times higher energies (compared to plastic deformation) in the $500-1000 \mathrm{kHz}$ frequency range. Higher frequencies of the AE signal from crack initiation and growth, compared to plastic deformation, can be explained by a shorter duration of the fracture process than that of deformation by multiple dislocation slip. Higher peak frequencies for steel brittle fracture, compared to plastic deformation, have been reported during tensile testing of dual-phase steels [10, 16]; however, absolute values of peak frequencies varied with steel microstructure. More detailed investigation is required to quantify dependences between AE signal parameters and steel microstructure and fracture mode. 
Voltage (mV) vs Time ( $\mu \mathrm{s})$

Power (dB) vs Frequency $(\mathrm{kHz})$
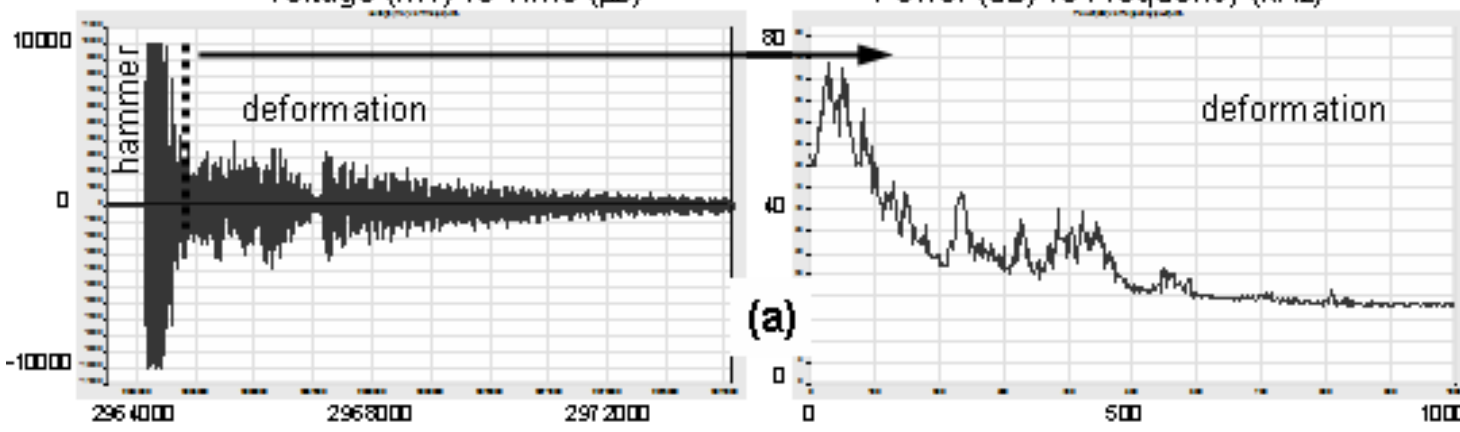

(a)

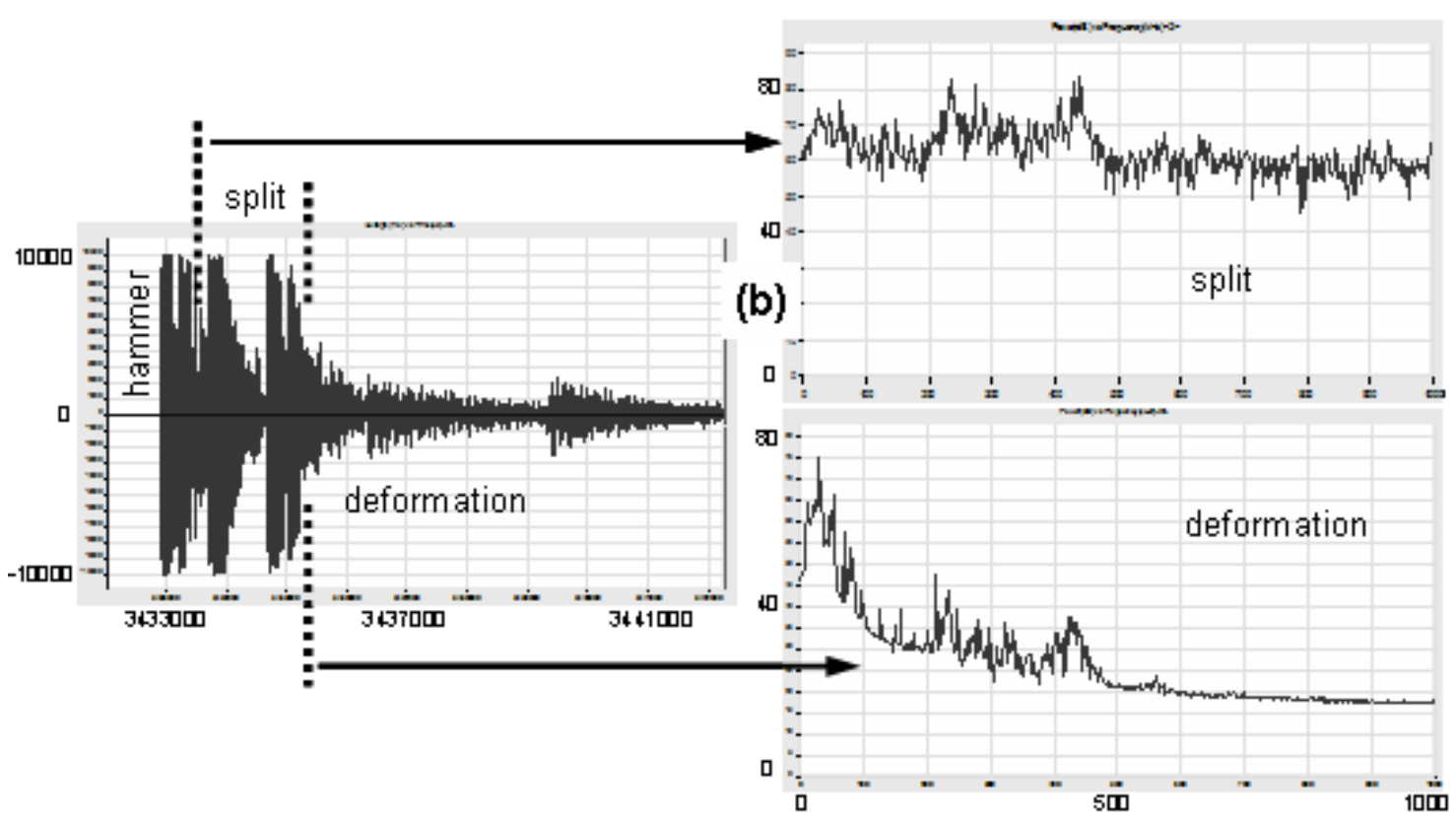

Figure 3 Acoustic waves (left) and power spectra (right) during testing of strip steel samples at (a) $60 \mathrm{~J}$ and (b) $80 \mathrm{~J}$ impact energies
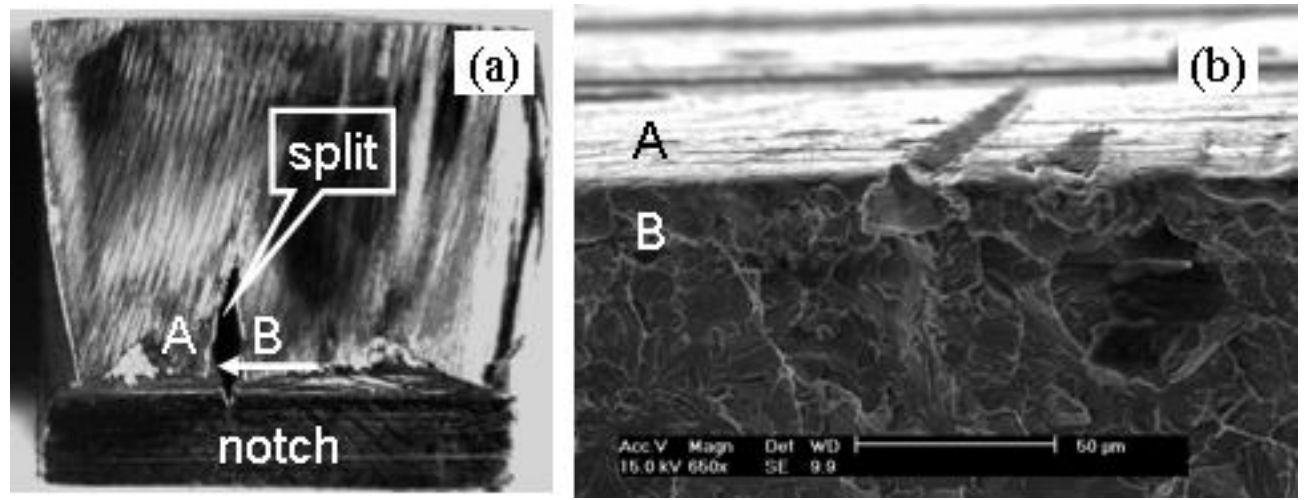

Figure 4 (a) Optical micrograph of the sample cross section (A) through the notch showing a split and (b) scanning electron micrograph of the fracture surface (B) in the strip steel sample after testing at $80 \mathrm{~J}$ impact energy. 


\section{Conclusions}

Acoustic emission monitoring technique has been used for the first time during low energy impact testing of high strength strip steels. A possibility to detect an acoustic signal originating from brittle split/crack formation on the background signal from plastic deformation has been shown. Peak frequency of the AE signal has been identified to be $<50 \mathrm{kHz}$ for the deformation of ferrite and to be in the range of $200-500 \mathrm{kHz}$ for the transgranular cleavage of ferrite.

\section{Acknowledgement}

The authors would like to acknowledge the Schools of Metallurgy and Materials, and Electrical, Electronic and Computer Engineering for the provision of test facilities at the University of Birmingham. Personal gratitude is to Professor Clive Roberts, Birmingham Centre for Railway Research and Education, for the provision of the AE monitoring system.

\section{References}

1. N. V. Novikov and V. E. Vainberg: Strength of Materials, 1977, 9, 1467-71.

2. M. Kotoul \& Z. Bilek: Int. J. Pres. Ves. \& Piping, 1990, 44, 291-307.

3. M. Akbari and M. Ahmadi: Physics Procedia, 2010, 3, 795 - 801.

4. C. K. Mukhopadhyay, K. V. Kasiviswanathan, T. Jayakumar, Baldev Raj: Journal of Material Science, 1993, 28, 145 - 54.

5. A.C.E. Sinclair, D.C. Connors and C.L. Formby: Materials Science and Engineering, 1977, 28,263 73.

6. T.C. Lindley, I.G. Palmer and C.E. Richards: Materials Science and Engineering, 1978, 32, 1 - 15.

7. M.N. Bassim, S.S. Lawrence and C.D. Liu: Engineering Fracture Mechanics, 1994, 47, 207 - 14.

8. K. Nam: Fatigue and Fracture of Engineering Materials and Structures, 1999, 22, 1103-09.

9. M.E. Biancolini, C. Brutti, G. Paparo, A. Zanini: International Journal of Fatigue, 2006, 28, 1820-25.

10. V. Chaswal, G. Sasikala, S.K. Ray, S.L. Mannan, B. Raj: Materials Science and Engineering A, 2005, 395, $251-64$.

11. M.N. Basim and M. Houssny-Emam: Materials Science and Engineering, 1984, 68, 79-83.

12. T.M. Roberts and M. Talebzadeh: Journal of Constructional Steel Research, 2003, 59, 695 - 712.

13. S. Yuyama, T. Kishi and Y. Hisamatsu: Nuclear Engineering and Design, 1984, 81, 345 - 55.

14. D.J Buttle and C.B. Scruby: NDT International, 1989, 22, 81 - 96.

15. H. Richter, J. Böhmert, H.-W. Viehrig: Nuclear Engineering and Design, 1999, 188, 241 - 54.

16. R. Khamedi, A. Fallahi, and H. Zoghi: International Journal of Recent Trends in Engineering, 2009, $1,30-34$. 